\title{
THE INFLUENCE OF PLAYING POSITION ON THE PHYSICAL, TECHNICAL, AND NETWORK VARIABLES OF SUB-ELITE PROFESSIONAL SOCCER ATHLETES
}

original paper

( ) University School of Physical Education in Wroclaw

DOI: https://doi.org/10.5114/hm.2020.100010

GIBSON PRAÇA ${ }^{1}$, LAURA BEATRIZ FALEIRO DINIZ ${ }^{1}$, FILIPE MANUEL CLEMENTE ${ }^{2,3}$, SARAH DA GLÓRIA TELES BREDT ${ }^{1}$, BRUNO COUTO ${ }^{1,4}$, ANDRÉ GUSTAVO PEREIRA DE ANDRADE ${ }^{1}$, ADAM LEE OWEN ${ }^{5,6}$

${ }^{1}$ Universidade Federal de Minas Gerais, Belo Horizonte, Brazil

${ }^{2}$ Escola Superior de Desporto e Lazer, Instituto Politécnico de Viana do Castelo, Viana do Castelo, Portugal

${ }^{3}$ Instituto de Telecomunicações, Delegação da Covilhã, Covilhã, Portugal

${ }^{4}$ University of the Sunshine Coast, Queensland, Australia

${ }^{5}$ Claude Bernard Lyon University, Lyon, France

${ }^{6}$ Seattle Sounders Football Club, Seattle, Washington, USA

\begin{abstract}
Purpose. Match analysis must adopt multidimensional performance indicators, which include analysing playing position influence in official matches. The study compared physical, technical, and network variables of Brazilian soccer athletes from different positions.

Methods. Overall, 17 professional soccer athletes ( 3 central defenders, 4 fullbacks, 5 central midfielders, 3 wide forwards, 2 central forwards) were monitored during 6 official matches. External load data were collected with a 10-Hz GPS device. The number of passes, shots, losses of ball possession, and balls recovered were coded. Athletes' network centralities were assessed with social network analysis.

Results. Central midfielders $(10.0 \pm 0.8 \mathrm{~km})$ and wide forwards $(10.4 \pm 0.4 \mathrm{~km})$ covered higher distances than central defenders $(10.2 \%$ and $14.7 \%$, respectively; $E S=0.392)$ and central forwards $(16.7 \%$ and $21.5 \%$, respectively; $E S=0.392)$. Wide forwards performed more high-intensity running $(17.8 \pm 2.5)$ than central defenders $(91.4 \% ; E S=0.377)$ and forwards $(88.9 \%$; $E S=0.377)$. Central defenders $(43.1 \pm 22.3)$ and fullbacks $(41.5 \pm 17.3)$ performed more passes than forwards ( $453.4 \%$ and $470.0 \%$, respectively; $E S=0.383)$. Central defenders $(0.16 \pm 0.04 \mathrm{AU})$ and fullbacks $(0.14 \pm 0.05 \mathrm{AU})$ presented a higher degree of centrality than all other positions $(E S=0.651)$. Wide forwards presented a higher degree of prestige $(0.13$ $\pm 0.05 \mathrm{AU})$ than central defenders $(325 \% ; E S=0.242)$. The highest prominence was observed for wide $(0.12 \pm 0.01 \mathrm{AU})$ and central forwards $(0.12 \pm 0.03 \mathrm{AU})(E S=0.509)$.
\end{abstract}

Conclusions. Physical and technical responses and network properties are position-specific among sub-elite athletes. Key words: soccer, match analysis, playing position, GPS devices, social network analysis, notational analysis

\section{Introduction}

The training process of soccer players must provide stimuli that enable the athletes to develop skills and actions demanded during the competition [1, 2]. As a result, this investigation focuses on the tactical behaviour and physical demands required from different players during a match [3]. According to previous literature in this area, it is essential to support the prescription of training loads and contents to the positional needs of the players [4]. Previous work referring to match demands led to an increased interest in the development of equipment, analysis, and techniques of match analysis, which is now one of the most prominent investigational areas of professional soccer [5-7]. Besides, considering the multifactorial characteristics

Correspondence address: Gibson Moreira Praça, Universidade Federal de Minas Gerais, Escola de Educação Física, Fisioterapia e Terapia Ocupacional, Departamento de Esportes. Av. Presidente Antônio Carlos, 6627, Campus Pampulha, CEP 31270-901, Belo Horizonte, Minas Gerais, Brazil, e-mail: gibson_moreira@yahoo.com.br

Received: March 21, 2020

Accepted for publication: March 21, 2020

Citation: Praça G, Diniz LBF, Clemente FM, Bredt SGT, Couto B, De Andrade AGP, Owen AL. The influence of playing position on the physical, technical, and network variables of sub-elite professional soccer athletes. Hum Mov. 2021;22(2):22-31; doi: https://doi.org/10.5114/hm.2020.100010. 
of performance in soccer [8], analysts seek information from different types of data such as physical, psychological, technical, and tactical. Although this need is evident in the practical context of training in soccer, there is currently a lack of research providing multidimensional analysis of players' performance in gamebased contexts $[9,10]$.

Nowadays, analysts are consensual about the existence of position-specific demands of soccer matches [11]. However, the magnitude and direction of the differences between playing positions are not agreed. For instance, some studies show that wide forwards (or wingers) cover greater total distances than other positions $[12,13]$, while others prove that total distances covered are greatest among central midfielders in official matches $[14,15]$. This absence of consensus is more prominent when considering the accelerations and high-intensity running actions since there are few studies available comprising these variables [16]. It is believed that the different categories of playing level participants in these studies may highlight the reason for the discrepancies in results. Although some studies compare the responses of different positions in U-14 [17], U-17 [13], and top players from European first divisions $[12,15]$, it is noticeable that most of the investigations focus on elite players (in professional squads or youth academies). Therefore, the specific knowledge of sub-elite players is scarce. Considering the reported differences between the responses of players with different levels of expertise [18], caution is suggested when generalizing data from top-level players to sub-elite groups. Thus, coaches in regional or lower-league clubs may lack correct information for adequately prescribing training loads to players from different positions.

In contrast with a large amount of data regarding the physical responses of players from different positions, there are considerably fewer studies focused on comprehending the impact of the specific positions on tactical-technical responses [6]. Traditionally, studies in this area have focused on basic actions, such as passing, tackling, or shooting $[19,20]$. At this point, a recent study reported position-specific demands related to passing, shooting, dribbling, and tackling [21] during UEFA Champions League. Position-specific technical actions are also dependent on players' nationality [22]; therefore, caution is recommended when interpreting results in a context different from that of the original study. Although these actions provide an idea of players' behaviour during the game, the general patterns of cooperation between teammates [23] are not captured in any context of a game or specific situation. For this reason, some types of analysis, such as social network analysis (SNA), have been proposed to complement the information provided by these traditional scouts used in soccer [24-26]. The main advantage of SNA is the possibility to easily assess the interactions established between the players, which is not present in the traditional analyses [27]. Moreover, the SNA approach provides information about players' decisional ability to create (e.g. degree prestige) and find (e.g. degree centrality) passing possibilities, which increases the comprehension of teams' tactical dynamics. Some authors have recently suggested that players' level of prominence is position-specific [26, 28, 29], with midfielders described as the most prominent players for building attacks. However, similarly to what is observed for the physical variables, all the data available refer to top-level teams and players, such as national teams during the World Cup. Nevertheless, sub-elite teams may present a more direct play style owing to their reduced technical ability in comparison with elite players. It is, however, possible that adopting a direct playing style or counter-attack may allow them to expose specific weaknesses within the opponents [30]. Therefore, the higher prominence found for top-level midfielders may not represent midfielders' performance in these sub-elite leagues.

From a practical perspective, the competitive scenario of soccer teams is markedly diverse. Although many studies have focused on large important competitions (such as national leagues in Spain and England and national teams' competitions), the majority of soccer matches are played in the sub-elite categories of the games pyramid structure. For example, the Brazilian Football Confederation had 742 professional clubs registered in 2018 and only 128 were selected for 1 of the 4 divisions of national competitions (about 17\%). Therefore, sub-elite clubs represent a particularly large percentage of professional teams and make a great contribution to the development of young players for high-level soccer. In summary, a multidimensional study of match demands in sub-elite players is required and, to the best of our knowledge, there is not enough data available in the literature on this topic.

Considering the aforementioned issues, high-quality information about the characteristics of the soccer game played by sub-elite teams is important for improving the training process within these contexts. Furthermore, it is known that playing positions define players' responses during the match. The absence of information regarding the influence of this variable on the physical, technical, and tactical performance of sub-elite players must be addressed. As a result, this study aimed to compare the physical (distances and accelerations), technical (frequency of passes, shots, 


\section{HUMAN MOVEMENT}

G. Praça et al., Match analysis in soccer

lost and won balls), and tactical behaviours (analysed by the micro-scale variables of SNA) of Brazilian regional players across a range of positions.

\section{Material and methods}

Experimental approach to the problem

This is a descriptive study in which professional sub-elite soccer players were monitored during official competitive matches in 2019. The players were monitored by GPS devices and all the matches were recorded for further analysis regarding the collection of technical and SNA variables. There were no interventions from the researcher during the procedures since collecting actual match-related data was the aim of the study. After the data collection, players were divided into groups depending on their playing position (central defenders, fullbacks, central midfielders, wide forwards, and central forwards), which was determined by analysing their heatmaps. Finally, all the dependent variables were compared between playing positions.

\section{Participants}

Six official matches played by 17 professional soccer players (age: $25.24 \pm 5.48$ years; body mass: $74.68 \pm$
$6.23 \mathrm{~kg}$; body fat: $10.89 \% \pm 1.24 \%)$ were analysed, totalizing 45 individual observations. There were 3 central defenders (12 observations), 4 fullbacks (10 observations), 5 central midfielders (13 observations), 3 wide forwards (4 observations), and 2 central forwards (6 observations). All players belonged to the same team, which participated in the first division of the regional competition of the state of Minas Gerais. Each player was classified by the coaching staff as a central defender (CD), fullback (FB), central midfielder (CM), wide forward (WF), or central forward (CF). If a player was assigned to more than one playing position, a heatmap of each game was used to determine their major role [26] (Figure 1). The following inclusion criteria were considered: (1) only data regarding players' participation in the whole match were included in the final analysis; (2) no significant changes on playing position within a game were allowed. Data from substitute players were not considered. During all the games, the team played in the 1-4-2-3-1 tactical formation, reducing the influence of positional variations on the reported responses.

\section{Procedures}

All the sessions of data collection took part during official matches of the regional championship during 2019. This competition is especially interesting to in-

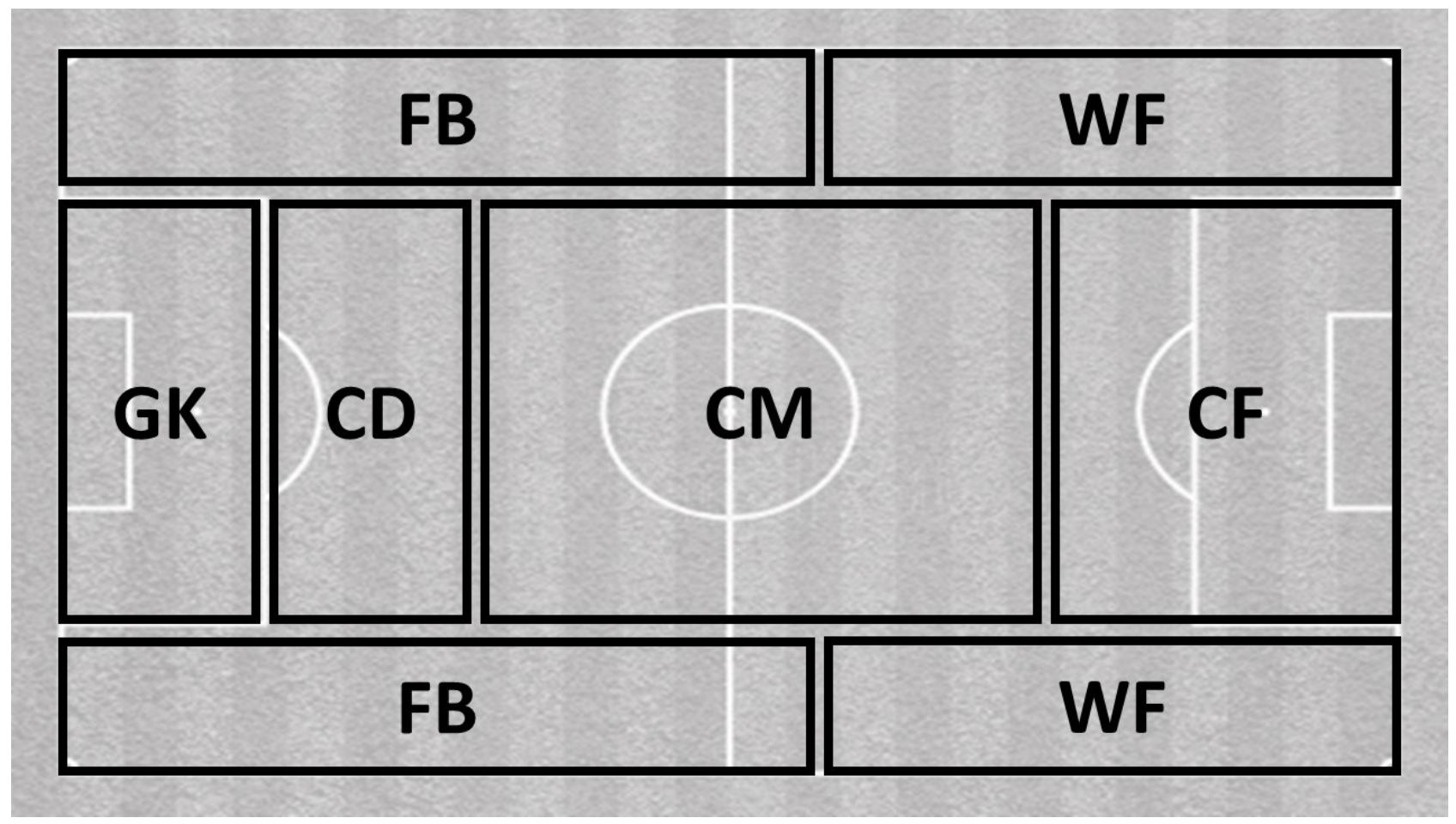

GK - goalkeeper, CD - central defender, FB - fullback, CM - central midfielder, WF - wide forward, CF - central forward

Figure 1. Classification of playing positions depending on the area mainly occupied in the field 
vestigate the influence of playing position on players' responses because the table comprises home and away matches against all the teams within a group (i.e., one home game and one away game against all the 3 opponents within the group). This condition provides a standardized influence of both levels of opposition [31] and match venue [32] on the reported measures.

During the matches, the players carried GPS devices (Polar ${ }^{\circledR}$, Team Pro, Kempele, Finland) within chest straps. The GPS was positioned at the beginning of the warm-up, to facilitate satellite identification and reduce missing data. After the match, the research team collected the devices and analysed the data using the Polar Team Pro online software. We synchronized the devices with the online system by positioning them into a dock station connected to a tablet (iPad, $6^{\text {th }}$ generation, Apple Inc., Cupertino, USA). We added the match time intervals within the Polar Team Pro online system to obtain the data.

\section{Measures}

\section{Physical responses}

The players' physical responses were recorded with $10-\mathrm{Hz}$ GPS devices, with an embedded $200-\mathrm{Hz}$ accelerometer (Polar ${ }^{\circledast}$, Team Pro, Kempele, Finland). The reliability of $10-\mathrm{Hz}$ GPS devices for analysing sportbased movements has been reported to be acceptable in previous studies [33]. In the present study, we analysed the following variables: total distance covered, distances covered at the speeds of $0.00-6.99 \mathrm{~km} / \mathrm{h}$, $7.00-14.99 \mathrm{~km} / \mathrm{h}, 15.00-19.99 \mathrm{~km} / \mathrm{h}, 20.00-24.99$ $\mathrm{km} / \mathrm{h}$, and $\geq 25.00 \mathrm{~km} / \mathrm{h}$, all measured in meters. The speed thresholds were adapted from previous studies [34-36], but with shorter intervals for analysing all movements. The large intervals used in those studies may not be sensitive to capture for analysing the time-motion profile or analysed thresholds with smaller intervals, but just for high-intensity actions. We also measured the number of accelerations (and decelerations) $\geq$ (or $\leq) 3.00 \mathrm{~m} / \mathrm{s}^{2}$ (and negative), $2.99-2.00 \mathrm{~m} / \mathrm{s}^{2}$ (and negative), and $1.99-1.00 \mathrm{~m} / \mathrm{s}^{2}$ (and negative), as well as the total number of sprints, which comprised speeds $>25 \mathrm{~km} / \mathrm{h}[12,13]$.

\section{Technical actions}

A technical scout with common variables adopted in previous studies was conducted [37-39]. We included the total number of successful passes, the percentage of successful passes, and the number of shots, lost balls, and recovered balls for each player during a match. Lost balls were defined as non-successful actions of passing, shooting, dribbling, or receiving that resulted in losing ball possession to the opposing team. Recovered balls were considered as tackles, interceptions, and duels that resulted in regaining ball possession. This information was collected through the observation of the videos by 3 experts. Within- and between-observer reliability coefficients were calculated to assure the quality of the observational data provided regarding the technical actions. For this purpose, 2 matches (33.33\%) were reassessed. The intraclass correlation coefficient (CCI 3,1) [40] equalled 0.997 and 0.980 for within- and between-observer reliability, respectively.

\section{Network analysis}

In the present study, centrality levels of the players during passing sequences were assessed with the SNA approach [41]. We used an observational protocol of a network analysis based on weighted digraphs. In team sports, the knowledge about the player who passes or receives the ball is important and the number of passes between specific players is also determinant information about the team's playing dynamics [41]. In this study, we considered only forward passes, i.e. those that created progression opportunities and allowed the attacking team to move ahead in the field. Each player received a code based on their playing position. A weighted adjacency matrix was built with the passing sequences (sequences of passes between teammates without the interference of opponents or loss of the ball). Figure 2 provides an example of a passing sequence and its respective adjacency matrix [26]. The final adjacency matrix of a match is the sum of all adjacency matrices built for all the passing sequences performed by a team. The observation and coding were made by 3 experts with experience in coding passing sequences.

Within- and between-observer reliability coefficients were calculated to assure the quality of the observational data provided regarding the network variables. For this purpose, 2 matches (33.33\%) were reassessed. The intraclass correlation coefficient (CCI 3,1) [40] equalled 0.997 and 0.980 for within- and between-observer reliability, respectively.

For this study, we only included the individual measures of the SNA. The centrality measures are related to the level of prominence of a player in the game and indicate how effectively each player participates in the offensive process. We analysed 3 variables re- 
Passing sequence

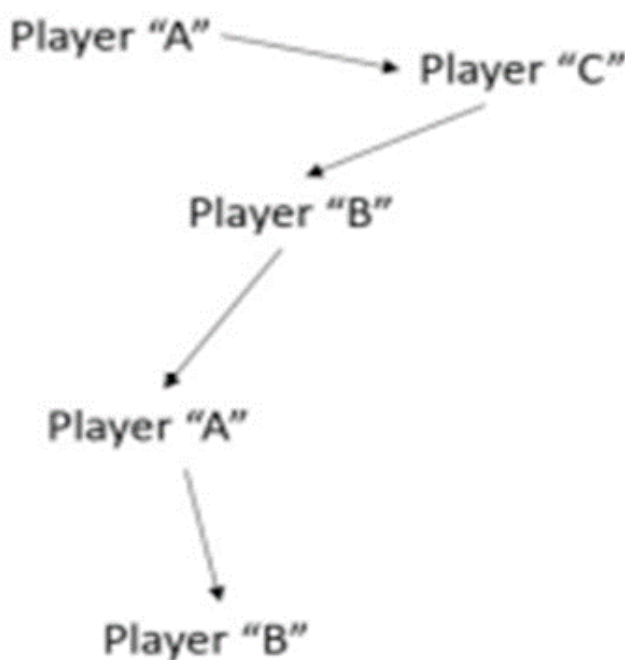

Adjacency matrix

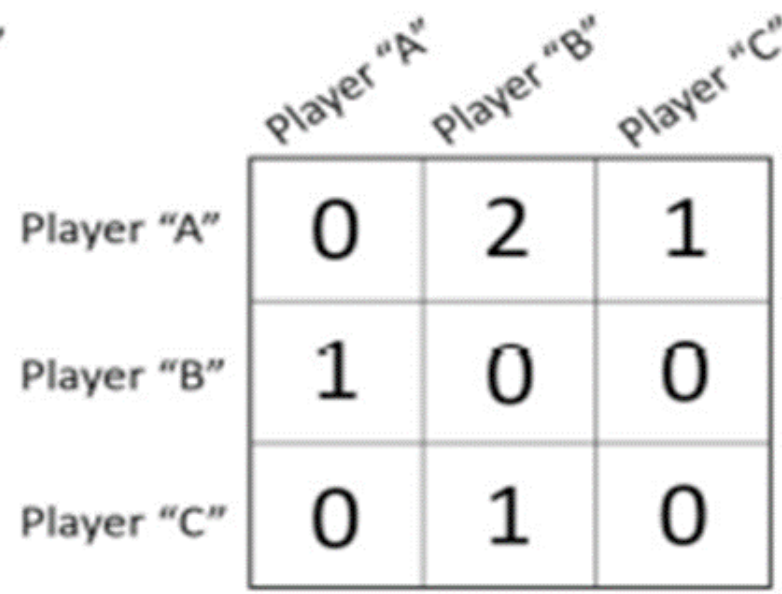

Figure 2. Example of a passing sequence used to build an adjacency matrix in social network analysis

lated to centrality: degree centrality, degree prestige, and page rank. Degree centrality indicates the percentage of passes performed by each player. Values range from 0 (lack of activity) to 1 (maximum exclusive centrality within the network). Degree prestige indicates the percentage of passes received by a player. Values range from 0 (lack of activity) to 1 (maximum exclusive prestige within the network). Page rank indicates a player's offensive popularity or the probability of a player to receive a pass. Values range from 0 (lack of probability) to 1 (maximum exclusive popularity within the network). All these variables were obtained with the use of the Social Network Visualizer software (SocNetV 1.9 $2005-2015$ by Dimitris V. Kalamaras, Greece).

\section{Data analysis}

Initially, we screened the data to find outliers or missing data. We also tested the normality (ShapiroWilk's test) and homoscedasticity (Levene's test) assumptions. A one-way ANOVA using the 'playing position' factor was applied to analyse the dependent variables. Also, Tukey's post-hoc test was conducted for pairwise comparisons. Partial eta squared effect sizes were calculated and classified as no effect $\left(\eta_{\mathrm{p}}^{2}<0.04\right)$, minimum effect $\left(0.04 \leq \eta_{\mathrm{p}}^{2}<0.25\right)$, moderate effect $\left(0.25 \leq \eta_{\mathrm{p}}^{2}<0.64\right)$, or strong effect $\left(\eta_{\mathrm{p}}^{2} \geq 0.64\right)$ [42]. For pairwise comparisons, the Cohen's $d$ effect size was also calculated and classified as small $(d=0.2)$, medium $(d=0.5)$, or large $(d=0.8)$ [43]. Statistical significance was set at $p<0.05$.

\section{Ethical approval}

The research related to human use has complied with all the relevant national regulations and institutional policies, has followed the tenets of the Declaration of Helsinki, and has been approved by the authors' institutional review board.

\section{Informed consent}

Informed consent has been obtained from all individuals included in this study.

\section{Results}

Table 1 presents the data regarding the physical responses of players from different positions. The general linear model indicated a main effect of position for the total distance covered (moderate effect), the number of sprints (moderate effect), the distances covered at speeds of 7.00-14.99 (moderate effect), 15.00-19.99 (moderate effect), and 20.00-24.99 km/h (moderate effect), the number of decelerations of 1.99-1.00 (minimum effect) and accelerations of 1.00-1.99 m/ $/ \mathrm{s}^{2}(\mathrm{mod}-$ erate effect). Pairwise comparisons revealed that CMs $(d=1.06, d=1.96$, respectively) and WFs $(d=1.93$, $d=3.70$, respectively) covered a higher total distance compared with CDs and CFs. WFs also performed more sprints ( $d=2.46, d=3.48$, respectively) and covered a higher distance at speeds of $20.00-24.99 \mathrm{~km} / \mathrm{h}$ ( $d=3.04, d=3.29$, respectively) than CDs and CFs. CMs $(d=1.16$ in comparison with CDs, $d=1.97$ in comparison with FBs, $d=2.31$ in comparison with CFs) and WFs $(d=1.38$ in comparison with CDs, $d=2.20$ in comparison with FBs, $d=2.52$ in comparison with $\mathrm{CFs}$ ) 


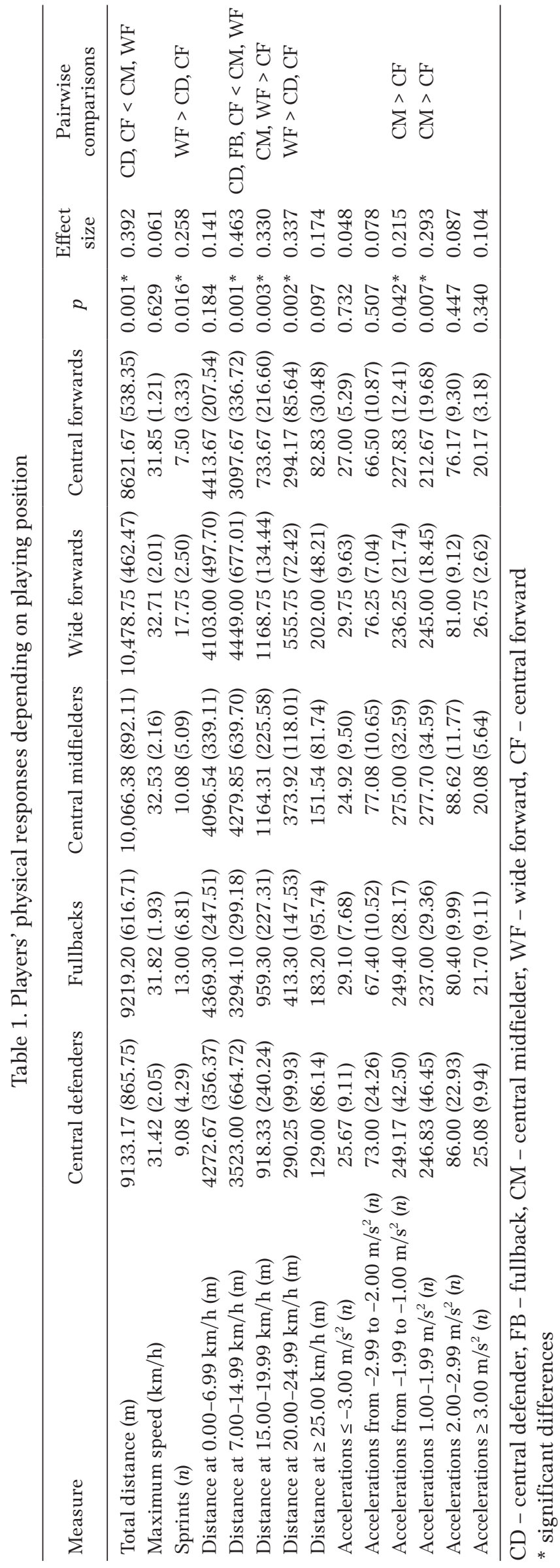

covered higher distances at speeds of 7.00-14.99 km/h compared with all other positions. CMc and WFs also covered higher distances at speeds of 15.00-19.99 km/h compared with CFs $(d=1.94, d=2.41$, respectively). Finally, CDs performed more accelerations $(d=0.95)$ and decelerations $(d=0.68)$ of $1.00-1.99 \mathrm{~m} / \mathrm{s}^{2}$ in comparison with CFs.

Table 2 presents the technical and tactical variables reported for each playing position during the matches. The general linear model indicated no effect on the percentage of successful passes. Main effect was reported regarding the playing position for degree centrality (strong effect), degree prestige (minimum effect), page rank (moderate effect), successful passes (moderate effect), shots (moderate effect), lost balls (moderate effect), and recovered balls (minimum effect). For the recovered balls, the pairwise comparisons showed no significant differences. Pairwise comparisons indicated that $\mathrm{CDs}(d=2.54$ in comparison with $\mathrm{CMs}$, $d=4.45$ in comparison with WFs, $d=4.80$ in comparison with CFs) and FBs $(d=1.69$ in comparison with CMs, $d=3.05$ in comparison with WFs, $d=3.32$ in comparison with CFs) presented lower values of degree centrality compared with all the other positions. CDs $(d=1.98$ in comparison with CMs, $d=3.57$ in comparison with WFs, $d=3.66$ in comparison with $\mathrm{CFs})$ and FBs $(d=0.94$ in comparison with CMs, $d=$ 2.52 in comparison with WFs, $d=2.74$ in comparison with $\mathrm{CFs}$ ) presented a lower page rank value than all other positions. Also, CDs $(d=2.23$ in comparison with CMs, $d=4.39$ in comparison with WFs, $d=1.67$ in comparison with CFs) and FBs $(d=0.49$ in comparison with CMs, $d=1.38$ in comparison with WFs, $d=0.25$ in comparison with CFs) lost less balls than all the other players. Besides, CDs and FBs presented a lower values of shots in comparison with CMs $(d=$ $1.24, d=1.30$, respectively) and CFs $(d=2.19, d=2.25$, respectively). CDs also presented lower values of degree prestige than WFs $(d=1.69)$. Finally, CDs and FBs presented higher values of successful passes than CFs $(d=2.01, d=2.69$, respectively).

\section{Discussion}

The multiple factor analysis of players' performance is a desirable pathway for match analysts and sports scientists nowadays. The availability of a wide range of match performance indicators can support better planning of training loads and contents in soccer, including positional specific requirements. Therefore, the purpose of this study was to compare the physical, technical, and tactical responses among Brazilian sub- 
Table 2. Players' network measures and technical responses depending on playing position

\begin{tabular}{|c|c|c|c|c|c|c|c|c|}
\hline Measure & $\begin{array}{c}\text { Central } \\
\text { defenders }\end{array}$ & Fullbacks & $\begin{array}{l}\text { Central } \\
\text { midfielders }\end{array}$ & $\begin{array}{l}\text { Wide } \\
\text { forwards }\end{array}$ & $\begin{array}{l}\text { Central } \\
\text { forwards }\end{array}$ & $p$ & $\begin{array}{l}\text { Effect } \\
\text { size }\end{array}$ & $\begin{array}{c}\text { Pairwise } \\
\text { comparisons }\end{array}$ \\
\hline Degree centra & $.16(0.04)$ & & $0.07(0.03)$ & $0.03(0.01)$ & $0.02(0.01)$ & & 0.651 & $\mathrm{CD}, \mathrm{FB}>\mathrm{CM}$, \\
\hline Degr & 0.06 & & 0.10 & 0.13 & & & 0.242 & \\
\hline Page rank (AU) & $0.04(0.03)$ & $0.08(0.02)$ & $0.11(0.04)$ & $0.12(0.01)$ & & $0.001^{*}$ & 0.509 & $\begin{array}{c}\mathrm{CD}<\mathrm{CM}, \mathrm{WF}, \mathrm{CF} ; \\
\mathrm{FB}<\mathrm{CF}\end{array}$ \\
\hline Succ & $41.58(22.38)$ & $43.10(17.37)$ & 25.85 & 15.00 & $9.17(3$ & $0.001 *$ & 0.383 & $\mathrm{CD}, \mathrm{FB}>\mathrm{CF}$ \\
\hline Successful passes (\%) & 83.37 (19.83) & $79.19(7.70)$ & $75.44(12.63)$ & $70.23(12.61)$ & $63.21(15.63)$ & 0.085 & 0.181 & \\
\hline Shots $(n)$ & $0.67(0.65)$ & & $2.54(2.02)$ & $1.75(0.50)$ & $3.17(1.47)$ & $0.001 *$ & 0.400 & $\mathrm{CD}, \mathrm{FB}<\mathrm{CM}, \mathrm{CF}$ \\
\hline Lost balls $(n)$ & $0.25(0.45)$ & $2.33(1.80)$ & $3.23(1.83)$ & $4.50(1.29)$ & $2.83(2.13)$ & $0.001^{*}$ & 0.462 & $\mathrm{CD}<\mathrm{FB}, \mathrm{CM}, \mathrm{WF}, \mathrm{CF}$ \\
\hline Recovered balls $(n)$ & $2.42(1.83)$ & $3.80(1.39)$ & $4.00(2.51)$ & $3.25(2.21)$ & $1.33(1.03)$ & 0.047 & 0.209 & \\
\hline
\end{tabular}

AU - arbitrary units, CD - central defender, FB - fullback, CM - central midfielder, WF - wide forward, $\mathrm{CF}$ - central forward * significant differences

elite soccer players from different positions. In general, the results showed that DFs and WFs presented the highest physical responses among all playing positions, which is in line with the literature [44]. It was also found that CDs presented the highest success rate of technical actions owing to their highest values of successful passes and lowest values of lost balls. These results partially corroborate previous studies on toplevel players.

CMs and WFs have been reported to cover the highest distances in official matches [45], which is in line with the results of the present study. Also, WFs have presented a higher frequency of sprints during a match in comparison with CDs $[13,15]$, and have also revealed higher ratings of perceived exertion than other positions on the pitch [44]. In modern soccer, WFs are largely demanded during the transition phases (both offensive and defensive). During these transitions, teams try to explore unbalanced situations emerging from the opposing teams [46], so the action speed is crucial for success. Therefore, owing to their specific roles during the transitions, the need to cover large distances at high speeds (to reduce the duration of the transition) is probably the reason why WFs perform more sprints than the other players. In the present study, CMs and WFs presented higher values of distance covered at speeds of $7.00-14.99 \mathrm{~km} / \mathrm{h}$, which is in line with a previous study [12]. The participation of these players in both attacking and defending may lead to a larger area covered by them and, consequently, be the reason for the higher total distance found for these players. This rationale may also be used to explain the highest frequency of accelerations achieved by CMs. Thus, in general, Brazilian sub-elite players present position-specific demands during matches, which is in line with previous studies.
Regarding the technical actions, a previous study reported a higher frequency of passes performed by midfielders in comparison with defenders [22], which is contrary to the results of the present study. However, CDs of high-level teams performed more passes, with a higher pass accuracy, than defenders from low-level teams [21], which indicates that the level of the analysed team impacts on the players' responses. We inferred that the teams analysed in this study presented a direct-play style because of the highest values of degree centrality observed in the defenders (which indicates the players who perform more passes) and the highest values of degree prestige found for the offensive players (which indicates the players that receive more passes). We speculate that this direct-play style, frequently adopted by lower-ranked teams (the context investigated in this study), may explain the present results. Moreover, a previous study reported that CMs, WFs, and CFs presented higher values of shots than CDs and FBs [21], which corroborates the current results. Indeed, these results are expected because these players are often closer to the goal and, consequently, have more shooting opportunities during a match. Interestingly, the frequency of shots was not higher for WFs in comparison with the more defensive players, which is contrary to the previously mentioned results. It maybe speculated that, in a direct-play style, WFs are often involved in defensive transitions. For this reason, they should be far from the opposing goal when shots occur in this play style. Therefore, sub-elite teams would present a reduced demand for shooting for players at the sides of the pitch. In general, it could be inferred that the technical demand of players from different positions is dependent on the competitive level, which denotes the need to carefully apply the results from high-level soccer contexts to inferior leagues. 
Previous studies suggested that midfielders were the most prominent players for building attacks [28]. However, in the present study, CMs, WFs, and CFs showed no differences for prominence, which indicates that these playing positions are equally important for building the attack. Interestingly, the similar level of prominence is probably influenced by the match status, since offensive players (mostly WFs) showed the highest prominence when the team was winning, with CDs revealing higher values when the team was drawing [26], which denotes that the style of play influences the players' prominence. As previously mentioned, the direct-play style could have impacted on the players' prominence and increased the prominence of CFs, who are usually less active than CMs and WFs. Moreover, since sub-elite teams usually practise in worse facilities (e.g. fields of poor quality) and have less skilled players, this direct-play style is a very common strategy. Therefore, the knowledge about the impact of this style on players' responses is relevant for planning match strategies. Nevertheless, this is the first study to provide a network analysis of forwarding passing sequences. We consider this approach useful for future studies to investigate details of teams' in-depth progression, a crucial ability for success in soccer. However, the lack of previous studies with a similar approach may have impacted on the abovementioned differences in the results. For this reason, future studies should compare data originated from full passing sequences with forward-passing ones. Finally, the tactical responses found in this study are slightly different from those usually reported in high-level competitions.

The results presented in this study may help coaches and technical staffs to better comprehend the dynamics of matches in the sub-elite level in respect to the position-specific demands that emerge from the game, which have not been previously established in the literature. However, some limitations should be mentioned. Firstly, the sample comprised only 6 matches. Although these were all the matches of this specific team in the competition, future studies should provide information about a large number of matches by, for example, investigating other sub-elite competitions or including data from different years. Besides, the classification of the playing positions in this study, in line with the available literature, was done from a discrete point of view, in which the functions inherent to each position were not taken into account. For example, CMs may present a very different behaviour under different occasions, becoming more defensive or offensive depending on the match status, the competition, the fatigue, the coach instructions, and other contextual factors. Therefore, future studies should deeply investigate the meaning of a playing position in a soccer match by considering the multiple functions that the same player can assume within a match.

\section{Conclusions}

The results of this study show that physical, technical, and tactical demands are position-specific in sub-elite players and should be taken into account to better plan the training contents for this specific group. Specifically, midfielders present the highest physical response among all playing positions. Moreover, this study is the first to provide a broadened point of view at the match demands of players from sub-elite Brazilian soccer leagues. Although only players from one country were assessed during the study, sub-elite leagues are common worldwide. Therefore, the results may be useful for designing training sessions in accordance with the demands of matches performed by sub-elite teams. Future studies are recommended to investigate if the current results apply to different tactical formations.

\section{Acknowledgements}

We are thankful to Fundação de Amparo à Pesquisa do Estado de Minas Gerais (FAPEMIG), Pró-Reitoria de Pesquisa da Universidade Federal de Minas Gerais, Coordenação de Aperfeiçoamento de Pessoal de Nível Superior (CAPES), and Polar Brazil for the financial support. We also thank Coimbra Sports for supporting the data collection.

This work is funded by Fundação para a Ciência e Tecnologia/Miniestrério/Ministério da Ciência, Tecnologia e Ensino Superior through national funds and when applicable co-funded EU funds under the project UIDB/50008/2020.

\section{Disclosure statement}

No author has any financial interest or received any financial benefit from this research.

\section{Conflict of interest}

The authors state no conflict of interest.

\section{References}

1. Clemente FM, Sarmento H. The effects of small-sided soccer games on technical actions and skills: a systematic review. Hum Mov. 2020;21(3):100-119; doi: 10.5114/hm.2020.93014.

2. Praça G, Barbosa GF, Murta C, Da Glória Teles Bredt S, Barreira D, Chagas MH, et al. Influence of floaters and positional status on players' tactical, physical, and 
physiological responses in soccer small-sided games. Hum Mov. 2020;21(3):54-63; doi: 10.5114/hm.2020. 91346.

3. Clemente FM, Sarmento H, Aquino R. Player position relationships with centrality in the passing network of world cup soccer teams: win/loss match comparisons. Chaos Solitons Fractals. 2020;133:109625; doi: 10.1016/ j.chaos.2020.109625.

4. Praça GM, Clemente FM, Pereira de Andrade AG, Perez Morales JC, Greco PJ. Network analysis in small-sided and conditioned soccer games: the influence of additional players and playing position. Kinesiology. 2017; 49(2):185-193; doi: 10.26582/k.49.2.8.

5. Sarmento H, Marcelino R, Anguera MT, Campaniço J, Matos N, Leitão JC. Match analysis in football: a systematic review. J Sports Sci. 2014;32(20):1831-1843; doi: 10.1080/02640414.2014.898852.

6. Sarmento H, Clemente FM, Araújo D, Davids K, McRobert A, Figueiredo A. What performance analysts need to know about research trends in association football (2012-2016): a systematic review. Sports Med. 2018; 48(4):799-836; doi: 10.1007/s40279-017-0836-6.

7. Santos PM, Lago-Penas C. Defensive positioning on the pitch in relation with situational variables of a professional football team during regaining possession. Hum Mov. 2019;20(2):50-56; doi: 10.5114/hm.2019.81019.

8. Aguiar M, Botelho G, Lago C, Maças V, Sampaio J. A review on the effects of soccer small-sided games. J Hum Kinet. 2012;33(1):103-113; doi: 10.2478/v10078-0120049-x.

9. Castellano J, Echeazarra I. Network-based centrality measures and physical demands in football regarding player position: is there a connection? A preliminary study. J Sports Sci. 2019;37(23):2631-2638; doi: 10.1080/02640414.2019.1589919.

10. Sarmento H, Clemente FM, Gonçalves E, Harper LD, Dias D, Figueiredo A. Analysis of the offensive process of AS Monaco professional soccer team: a mixed-method approach. Chaos Solitons Fractals. 2020;133:109676; doi: 10.1016/j.chaos.2020.109676.

11. Varley MC, Di Salvo V, Modonutti M, Gregson W, Mendez-Villanueva A. The influence of successive matches on match-running performance during an under-23 international soccer tournament: the necessity of individual analysis. J Sports Sci. 2018;36(5):585-591; doi: 10.1080/02640414.2017.1325511.

12. Mallo J, Mena E, Nevado F, Paredes V. Physical demands of top-class soccer friendly matches in relation to a playing position using global positioning system technology. J Hum Kinet. 2015;47:179-188; doi: 10.1515/hukin2015-0073.

13. Pettersen SA, Brenn T. Activity profiles by position in youth elite soccer players in official matches. Sports Med IntOpen. 2019;3(1):E19-E24; doi:10.1055/a-0883-5540.

14. Di Salvo V, Baron R, Tschan H, Calderon Montero FJ, Bachl N, Pigozzi F. Performance characteristics accord- ing to playing position in elite soccer. Int J Sports Med. 2007;28(3):222-227; doi: 10.1055/s-2006-924294.

15. Rivilla-García J, Calvo LC, Jiménez-Rubio S, ParedesHernández V, Muñoz A, van den Tillaar R, et al. Characteristics of very high intensity runs of soccer players in relation to their playing position and playing half in the 2013-14 Spanish La Liga season. J Hum Kinet. 2019;66:213-222; doi: 10.2478/hukin-2018-0058.

16. Bradley PS, Archer DT, Hogg B, Schuth G, Bush M, Carling C, et al. Tier-specific evolution of match performance characteristics in the English Premier League: it's getting tougher at the top. J Sports Sci. 2016;34(10): 980-987; doi: 10.1080/02640414.2015.1082614.

17. Nikolaidis PT. Physical fitness in female soccer players by player position: a focus on anaerobic power. Hum Mov. 2014;15(2):74-79; doi: 10.2478/humo-2014-0006.

18. Nikolaidis P, Ziv G, Lidor R, Arnon M. Inter-individual variability in soccer players of different age groups playing different positions. J Hum Kinet. 2014;40(1):213225; doi: 10.2478/hukin-2014-0023.

19. Carling C. Influence of opposition team formation on physical and skill-related performance in a professional soccer team. Eur J Sport Sci. 2011;11(3):155-164; doi: 10.1080/17461391.2010.499972.

20. Kempton T, Sullivan C, Bilsborough JC, Cordy J, Coutts A. Match-to-match variation in physical activity and technical skill measures in professional Australian football. J Sci Med Sport. 2015;18(1):109-113. doi: 10.1016/j.jsams.2013.12.006.

21. Yi Q, Jia H, Liu H, Gómez MÁ. Technical demands of different playing positions in the UEFA Champions League. Int J Perform Anal Sport. 2018;18(6):926-937; doi: $10.1080 / 24748668.2018 .1528524$.

22. Gai Y, Volossovitch A, Lago C, Gómez M-Á. Technical and tactical performance differences according to player's nationality and playing position in the Chinese Football Super League. Int J Perform Anal Sport. 2019; 19(4):632-645; doi: 10.1080/24748668.2019.1644804.

23. Gréhaigne JF, Godbut P. Tactical knowledge in team sports from a constructivist and cognitivist perspective. Quest. 1995;47(4):490-505; doi: 10.1080/003362 97.1995.10484171.

24. Grund TU. Network structure and team performance: the case of English Premier League soccer teams. Soc Networks. 2012;34(4):682-690; doi: 10.1016/j.socnet. 2012.08.004.

25. Peixoto D, Praça GM, Bredt ST, Clemente FM. Comparison of network processes between successful and unsuccessful offensive sequences in elite soccer. Hum Mov. 2017;18(5):48-54; doi: 10.1515/humo-2017-0044.

26. Praça GM, Lima BB, Teles Bredt S da G, e Sousa RB, Clemente FM, Pereira de Andrade AG. Influence of match status on players' prominence and teams' network properties during 2018 FIFA World Cup. Front Psychol. 2019;10:695; doi: 10.3389/fpsyg.2019.00695.

27. Clemente FM, José F, Oliveira N, Lourenço Martins FM, Mendes RS, Figueiredo AJ, et al. Network structure 
and centralization tendencies in professional football teams from Spanish La Liga and English Premier Leagues. J Hum Sport Exerc. 2016;11(3):376-389; doi: 10.14198/jhse.2016.113.06.

28. Clemente FM, Lourenço Martins FM, Wong DP, Kalamaras D, Mendes RS. Midfielder as the prominent participant in the building attack: a network analysis of national teams in FIFA World Cup 2014. Int J Perform Anal Sport. 2015;15(2):704-722; doi: 10.1080/ 24748668.2015.11868825.

29. Clemente FM, Sarmento H, Praça GM, Nikolaidis PT, Rosemann T, Knechtle B. Variations of network centralities between playing positions in favorable and unfavorable close and unbalanced scores during the 2018 FIFA World Cup. Front Psychol. 2019;10:1802; doi: 10.3389/fpsyg.2019.01802.

30. Malta P, Travassos B. Characterization of the defenseattack transition of a soccer team [in Portuguese]. Motricidade. 2014;10(1):27-37; doi: 10.6063/motricidade.1544.

31. Folgado H, Duarte R, Fernandes O, Sampaio J. Competing with lower level opponents decreases intra-team movement synchronization and time-motion demands during pre-season soccer matches. PLoS One. 2014; 9(5):e97145; doi: 10.1371/journal.pone.0097145.

32. García-Rubio J, Gómez MÁ, Lago-Peñas C, Ibáñez JS. Effect of match venue, scoring first and quality of opposition on match outcome in the UEFA Champions League. Int J Perform Anal Sport. 2015;15(2):527-539; doi: 10.1080/24748668.2015.11868811.

33. Köklü Y, Arslan Y, Alemdaroğlu U, Duffield R. Accuracy and reliability of SPI ProX global positioning system devices for measuring movement demands of team sports. J Sports Med Phys Fitness. 2015;55(5):471-477.

34. Baptista I, Johansen D, Figueiredo P, Rebelo A, Arne Pettersen S. A comparison of match-physical demands between different tactical systems: 1-4-5-1 vs 1-3-5-2. PLoS One. 2019;14(4):e0214952.

35. Figueira B, Gonçalves B, Masiulis N, Sampaio J. Exploring how playing football with different age groups affects tactical behaviour and physical performance. Biol Sport. 2018;35(2):145-153; doi: 10.5114/biolsport. 2018.71603.

36. Gómez-Carmona CD, Gamonales JM, Pino-Ortega J, Ibáñez SJ. Comparative analysis of load profile between small-sided games and official matches in youth soccer players.Sports. 2018;6(4):173; doi: 10.3390/sports6040173.

37. Konefał M, Chmura P, Kowalczuk E, Figueiredo AJ, Sarmento H, Rokita A, et al. Modeling of relationships between physical and technical activities and match outcome in elite German soccer players. J Sports Med Phys Fitness. 2019;59(5):752-759; doi: 10.23736/ S0022-4707.18.08506-7.

38. Lago-Peñas C, Gómez-Ruano MÁ, Gai Y. Styles of play in professional soccer: an approach of the Chinese Soccer Super League. Int J Perform Anal Sport. 2017;17(6): 1073-1084; doi: 10.1080/24748668.2018.1431857.
39. Liu H, Gómez M-A, Gonçalves B, Sampaio J. Technical performance and match-to-match variation in elite football teams. J Sports Sci. 2016;34(6):509-518; doi: 10.1080/02640414.2015.1117121.

40. Weir JP. Quantifying test-retest reliability using the intraclass correlation coefficient and the SEM. J Strength Cond Res. 2005;19(1):231-240; doi: 10.1519/15184.1.

41. Clemente FM, Lourenço Martins FM, Mendes RS. Social network analysis applied to team sports analysis. Dordrecht: Springer International Publishing; 2016.

42. Ferguson CJ. An effect size primer: a guide for clinicians and researchers. Prof Psychol Res Pract. 2009;40(5): 532-538; doi: 10.1037/a0015808.

43. Cohen J. Statistical power analysis for the behavioral sciences. New York: Lawrence Erlbaum Associates; 1988.

44. Owen AL, Dunlop G, Rouissi M, Haddad M, Mendes B, Chamari K. Analysis of positional training loads (ratings of perceived exertion) during various-sided games in European professional soccer players. Int J Sports Sci Coach. 2016;11(3):374-381; doi: 10.1177/1747954116 644064.

45. Abbott W, Brickley G, Smeeton NJ. Physical demands of playing position within English Premier League academy soccer. J Hum Sport Exerc. 2018;3(2):285-295; doi: 10.14198/jhse.2018.132.04.

46. Hughes M, Lovell T. Transition to attack in elite soccer. J Hum Sport Exerc. 2019;14(1):236-253; doi: 10.14198/ jhse.2019.141.20. 